\title{
Comparisons of school and home-packed lunches for fruit and vegetable dietary behaviours among school-aged youths
}

\author{
Jennifer C Taylor ${ }^{1,2,3, *}$, Carolyn Sutter ${ }^{4,5}$, Lenna L Ontai ${ }^{5}$, Adrienne Nishina ${ }^{4}$ and \\ Sheri Zidenberg-Cherr ${ }^{2}, 3,6$ \\ 'The Design Lab, University of California, San Diego, 9500 Gilman Drive, MC 0436, La Jolla, CA 92093-0109, \\ USA: ${ }^{2}$ Department of Nutrition, University of California, Davis, Davis, CA, USA: ${ }^{3}$ Center for Nutrition in Schools, \\ University of California, Davis, Davis, CA, USA: ${ }^{4}$ Family Resiliency Center, University of Illinois, Urbana-Champaign, \\ Urbana, IL, USA: ${ }^{5}$ Department of Human Ecology, University of California, Davis, Davis, CA, USA: ${ }^{6}$ University of \\ California Agriculture and Natural Resources, Davis, CA, USA
}

Submitted 31 July 2018: Final revision received 6 December 2018: Accepted 3 January 2019: First published online 26 February 2019

\begin{abstract}
Objective: School-based interventions and policies encourage youths to include and consume fruits and vegetables at lunchtime via school lunches, but limited research has examined how these behaviours compare when youths have homepacked lunches. The objective of the present study was to compare fruit and vegetable contents and consumption among students having school or homepacked lunches over the school week.

Design: Participants were observed over five consecutive days at school lunchtime. Trained analysts estimated students' lunchtime fruit and vegetable contents and consumption using digital imaging. Mixed models examined associations between fruit and vegetable dietary behaviours and lunch source (school $v$. home-packed), controlling for student gender, grade and school.

Setting: Three elementary schools in northern California, USA.

Participants: Fourth-, fifth- and sixth-grade students ( $n_{\text {children }} 315 ; n_{\text {observations }} 1421$ ). Results: Students were significantly less likely to have and to consume fruits and vegetables (all $P<0.05$ ) when having home-packed lunches, compared with when having school lunches. Among those who did have or did consume these foods, having a home-packed lunch was associated with consuming significantly less fruit $(P<0 \cdot 05)$ but no differences for other dietary outcomes.

Conclusions: The study adds to a growing body of literature indicating shortfalls in fruit and vegetable contents and consumption associated with having a home-packed lunch, relative to having a school lunch. Findings suggest that school-based interventions, particularly when targeting home-packed lunches, should focus on whether or not these foods are included and consumed, with less emphasis on quantities.
\end{abstract}

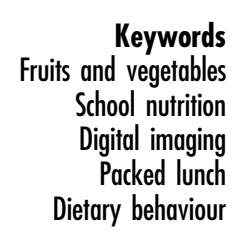

Increasing consumption of fruits and vegetables from an early age may improve health outcomes. For example, fruits and vegetables may displace low-nutrient, energydense foods in a child's diet that are associated with increased risk of obesity ${ }^{(1)}$. Additionally, greater consumption of fruits and vegetables is associated with reduced risk of chronic diseases such as $\mathrm{CVD}^{(2)}$. Schools can play an instrumental role in addressing the low adherence to fruit and vegetable recommendations among US children ${ }^{(3,4)}$, since youths consume up to half of their energy intake at school ${ }^{(5,6)}$. The introduction of updated nutrition standards for the National School Lunch Program (NSLP) in $2012^{(7)}$ has been associated with improvements in these dietary behaviours at school among NSLP participants ${ }^{(8)}$. However, close to half of students bring foods from home in packed lunches, which are not subject to these federal standards ${ }^{(9)}$.

A growing body of research observing lunchtime dietary behaviours indicates that contents of home-packed lunches are often of low nutritional quality and fall short of federal nutrition guidance ${ }^{(10-14)}$. Recognizing these shortfalls associated with home-packed lunches has stimulated the development of interventions targeting these lunches and addressing the home environment ${ }^{(15,16)}$.

Few studies have directly compared school and homepacked lunches with respect to students' fruit and vegetable behaviours. Studies to date have indicated that home-packed lunches less often contain any fruits and 
vegetables when compared with school lunches ${ }^{(17,18)}$. These studies addressed whether or not fruits and vegetables are included in the lunch, but the extent to which the quantities of contents differ by lunch source is unknown. Comparisons of what is ultimately consumed from these lunch sources are also needed. While students having school lunches are required to include at least onehalf cup of fruits and vegetables, a large proportion of fruits and vegetables contained within a school lunch may go uneaten, making contents (i.e. what is served to, and/or selected by, the student) a weak proxy for consumption $^{(19,20)}$. By contrast, parents report that their decisions to pack a lunch from home are driven by the desire to offer foods they know their child likes and will eat, potentially resulting in the consumption of most or all of any fruit and vegetable contents ${ }^{(21)}$. Together, these findings suggest that students having home-packed lunches may consume equal, if not more, fruits and vegetables than those having school lunches, despite on average containing fewer servings of them. Hur et al. ${ }^{(22)}$ found that elementary-school students having home-packed lunches consumed more fruits but less vegetables than students having school lunches. This finding for vegetable consumption contrasts with the pattern reported for lunch contents, underscoring the importance of understanding both what is included and what is ultimately eaten from these lunch sources.

Finally, it is important to consider the types of methods used to examine dietary behaviours. Self-reported dietary assessment methods have well-known limitations related to respondent burden and measurement error that can limit their feasibility and validity when working with school-aged youths ${ }^{(23,24)}$. These limitations may be mitigated by working with observation-based plate waste methods that capture information on foods included (contents) and eaten (consumption) within a given meal occasion, such as the lunch period. While these methods are increasingly applied to studies examining homepacked lunches, limited research has observed school and home-packed lunches simultaneously, and fewer studies have observed both what is included and what is actually consumed. In addition, studies typically rely on a single lunch observation to measure dietary behaviour, but children's and adolescents' dietary behaviours show a high degree of day-to-day variability ${ }^{(25,26)}$. Measuring behaviours over multiple days may capture more reliable estimates of differences between school and home-packed lunches.

The objective of the present study was to compare students' fruit and vegetable dietary behaviours across the school week when having a school $v$. a home-packed lunch.

\section{Methods}

\section{Participants}

Participants were 315 fourth-, fifth- and sixth-grade students participating in the Parents to Peers study, a project examining social and contextual correlates of students' dietary behaviours at lunchtime ${ }^{(27)}$. This sample size was determined based on a primary study aim regarding peer interactions at lunchtime. Students were recruited from three elementary schools within one California school district, with schools selected on the basis of having varied proportions of students eligible for free or reduced-price meals through the NSLP (school A = 34\%; school B=76\%; school $\mathrm{C}=53 \%$ ). Of the 541 students eligible to participate, parental consent and student assent was obtained for 321 students (68\% of consent forms returned, $87 \%$ of returned forms provided consent). Participation rates varied across schools based on percentage of consent forms returned (61, 82 and $66 \%$ from schools $\mathrm{A}, \mathrm{B}$ and C, respectively) and the percentage of these forms providing consent (86, 79 and 94\% from schools A, B and C respectively). Dietary data were available for 319 students. Because the study focused on students having either a school or a home-packed lunch on a given day, observations where students chose both lunch types were excluded from analyses, resulting in a final sample of 315 students.

\section{Study design}

Recruitment and data collection occurred from January to April 2016. Information packets including consent forms were distributed to students through each classroom, on average 2.5 weeks prior to each 1 -week period of data collection. A \$US 5 incentive was provided for returning a signed parent consent form (regardless of whether the parent provided consent or declined to participate). Students were compensated for their participation (\$US 1 to the student and \$US 1 to the student's classroom per day). Using a micro-longitudinal study design, data were collected from each participant over a period of five consecutive school days (i.e. a 1-week period), such that lunch source could vary from day to day for a student. All participants in a given grade completed the study during the same week, with data collection completed over seven weeks (thirty-five days). Parents completed demographic surveys, and lunchtime observations using digital imaging were conducted each day of the study to determine lunch source and dietary intake. The study was approved by the University of California, Davis, Institutional Review Board.

\section{Procedure}

Fruit and vegetable contents and consumption were determined daily for five days for each student using digital imaging procedures adapted from previous studies $^{(12,28)}$. Protocols applied in the present study, including feasibility and reliability testing, are described in more detail elsewhere ${ }^{(29)}$. Briefly, digital images of lunch contents were collected prior to lunch (for home-packed lunches) or at the start of the lunch period as students exited the lunch line (for school lunches). Digital images 
of plate waste remaining were collected at the end of lunch, including food remains and empty packaging, for both school and home-packed lunches. Students were instructed to wait to dispose of any food or packaging until after plate waste imaging, and field observation notes were collected during lunch to account for instances where foods were gained or removed (e.g. early disposal or food sharing). Digital images were collected of lunch contents while positioned in a school lunch tray and/or on a mat board marked with one-inch gridlines. In addition to digital images, supplemental information on food preparation was gathered for school lunches (menu data collected from school nutrition services) and homepacked lunches (written descriptions collected by trained researchers).

Following data collection, trained researchers with established inter-rater reliability determined food types and quantities from written and image records using visual estimation methods drawn from prior studies ${ }^{(28-30)}$. Foods were first identified from digital images of lunch contents, using supplemental information to aid food identification as needed. For example, written descriptions of packed lunch contents were collected for mixed dish items such as sandwiches to aid in coding its individual components. The quantity included for each of these items in the lunch was then determined by using manufacturer labels (prepackaged items), school menu information (for preportioned items) or visual estimation procedures (all other items). Foods were visually estimated by either: (i) determining the item's dimensions, using the one-inch gridlines of the mat board in the image (e.g. diameter of an apple); or (ii) using a series of over 2000 reference images that displayed foods in varied portion sizes (e.g. images of baby carrots displaying portions in $10 \mathrm{~g}$ increments). Finally, food consumption was estimated by comparing images of initial lunch contents with images of plate waste to determine the percentage consumed for each item. Food descriptions and quantities were entered into the Nutrition Data System for Research (NDSR) software version 2014, developed by the Nutrition Coordinating Center (NCC), University of Minnesota, Minneapolis, MN, USA ${ }^{(31)}$. Fruit and vegetable outcomes were each summed across all items in a lunch. Fruit outcomes excluded fruit juice given its lower nutrient density, particularly dietary fibre, compared with whole fruits, and given the emphasis on increasing whole fruits within national dietary guidance ${ }^{(32)}$. Vegetable outcomes excluded fried potatoes given the high energy density relative to other vegetable sub-categories. Quantities were reported in half-cup servings based on the NCC Food Group Serving Count System.

\section{Analyses}

Descriptive statistics were used to describe student demographics, lunch source patterns across the school week and prevalence of each dietary behaviour (fruit contents included, fruit consumption, vegetable contents included, vegetable consumption) across the total sample of observations. Mixed models were used to examine dietary behaviours as a function of daily lunch source (school lunch, home-packed lunch), incorporating a random intercept to account for nesting of observations within students. Dietary behaviour distributions were zeroinflated with positive skewness. For example, this distribution for fruit consumption indicated that many students did not consume any fruit on a given day of the week, and that among those who did consume fruit, most consumed smaller quantities (i.e. up to 1 half-cup serving) while far fewer students consumed larger quantities (i.e. greater than 3 half-cup servings). Given this pattern across all four dietary outcomes, each dietary outcome was examined in two models: (i) a binary component examining whether or not the behaviour occurred (e.g. fruit quantity included $>0$ half-cup servings; fruit quantity included $=0$ half-cup servings); and (ii) a continuous component examining quantities, when the behaviour did occur (e.g. quantity of fruit included, given that quantity included $>0$ half-cup servings). This approach was chosen to address not only how much was included and consumed of these foods across lunch sources (the continuous outcome), but also to describe the extent to which these dietary behaviours are initiated at all (the binary component).

Binary outcomes were examined using logistic mixed models. Log-odds were transformed to probabilities and odds ratios to estimate the probability of each dietary behaviour occurring and to compare the likelihood for home-packed lunches, relative to school lunches (reference group). Continuous outcomes were examined using linear mixed models. A series of data transformations were examined, and square-root transformations were selected on the basis of Shapiro-Wilks normality tests $(W>0.95)$ and inspection of residual plots for each model. The fixedeffects parameter estimates and confidence intervals for these continuous outcomes are presented as backtransformed least-squares means, using a Tukey adjustment for multiple comparisons. Based on comparisons of model fit (assessed by log-likelihood and Akaike information criterion), all models were adjusted for student gender, grade and school. Analyses were conducted in the statistical software package SAS version 9.4 using PROC NLMIXED and PROC MIXED.

\section{Results}

Sample characteristics are summarized in Table 1. A total of 1421 observations were collected from 315 students. Approximately half of these observations were of school lunches (53\%). Aggregated across the week, most students consistently had a school lunch every day (45\%) or consistently had a home-packed lunch (37\%), while $18 \%$ 
of students varied day-to-day in lunch source. These patterns for lunch source were associated with school $\left(\chi_{4,315}^{2}=107 \cdot 0 ; P<0 \cdot 0001\right)$, where most school A students consistently had a packed lunch (60\%), most school B students consistently had a school lunch (93\%) and school C students varied (i.e. $37 \%$ consistently had a school lunch, $41 \%$ consistently had a packed lunch and $22 \%$ varied in lunch source)

Table 1 Characteristics of participants in a study examining dietary behaviours associated with lunch source among elementary-school students ( $\left.n_{\text {children }} 315\right) \dagger$, northern California, USA, January-April 2016

\begin{tabular}{lrr}
\hline & $n$ & \\
\hline Gender & & \\
Boy & 140 & 44 \\
Girl & 175 & 56 \\
Grade & & \\
4 & 106 & 34 \\
5 & 99 & 31 \\
6 & 110 & 35 \\
School & & \\
A & 88 & 28 \\
B & 75 & 24 \\
C & 152 & 48 \\
Race/ethnicity & & 9 \\
African American/Black & 27 & 7 \\
Asian/Pacific Islander & 21 & 18 \\
Caucasian/White & 112 & 26 \\
Latino & 55 & 3 \\
Multi-ethnic & 78 & 16 \\
Other & 10 & 20 \\
Household income & & 19 \\
< \$US 20 000 & 47 & 9 \\
\$US 20 000-39 999 & 57 & 26 \\
\$US 40 000-59 999 & 54 & \\
\$US 60 000-79 999 & 31 & \\
\$US 80 000-99999 & 25 & \\
$\geq$ \$US 100 0000 & 76 & \\
\hline
\end{tabular}

†Sample sizes differ due to missing data.

\section{Fruit contents}

The probability of including fruit was 0.97 and 0.86 when having a school or a home-packed lunch, respectively. When having a home-packed lunch, students were $81 \%$ less likely to include fruit than when having school lunches (OR $=0.19$ (95\% CI 0.11, 0.35), $P<0.001$; Table 2). Fruit quantities were examined after excluding two extreme observations where fruit contents exceeded 8 servings. On days when fruit was included ( $90 \%$ of school and $72 \%$ of home-packed lunch observations), the quantities included were not significantly different between school and home-packed lunches; lunches contained an average of 1.1 half-cup servings of fruit (Table 3).

\section{Fruit consumption}

The probability of consuming fruit was 0.87 when having a school lunch, compared with 0.68 when having a homepacked lunch. Students were $69 \%$ less likely to consume fruit when having a home-packed lunch compared with when having a school lunch $(\mathrm{OR}=0.31$ (95\% CI 0.18, $0.52), P<0.001$; Table 2). On days when fruit was consumed $(73 \%$ of school and $58 \%$ of home-packed lunch observations), the quantities consumed were significantly greater among home-packed lunches (mean $=0.86(95 \%$ CI $0.78,0.95)$ half-cup servings) than school lunches (mean $=0.65(95 \%$ CI $0.58,0.71)$ half-cup servings, $P<0 \cdot 001$; Table 3).

\section{Vegetable contents}

The probability of including vegetables was 0.47 and 0.35 when having a school lunch or a home-packed lunch, respectively. Students were $40 \%$ less likely to include vegetables when having a home-packed lunch compared

Table 2 Associations between lunch source and odds of including and consuming fruits and vegetables among elementary-school students ( $\left.n_{\text {children }} 315\right)$ observed over five school days ( $\left.n_{\text {observations }} 1421\right)$, northern California, USA, January-April 2016

\begin{tabular}{|c|c|c|c|c|c|c|c|c|}
\hline & \multicolumn{2}{|c|}{$\begin{array}{c}\text { Fruit contents } \dagger \\
\left(n_{\text {children }} 315,\right. \\
\left.n_{\text {observations }} 1421\right)\end{array}$} & \multicolumn{2}{|c|}{$\begin{array}{c}\text { Fruit consumption } \\
\left(n_{\text {children }} 309,\right. \\
\left.n_{\text {observations }} 1221\right)\end{array}$} & \multicolumn{2}{|c|}{$\begin{array}{c}\text { Vegetable contents } \\
\left(n_{\text {children }} 315,\right. \\
\left.n_{\text {observations }} 1421\right)\end{array}$} & \multicolumn{2}{|c|}{$\begin{array}{c}\text { Vegetable consumption } \\
\left(n_{\text {children }} 312,\right. \\
\left.n_{\text {observations }} 1300\right)\end{array}$} \\
\hline & OR & $95 \% \mathrm{Cl}$ & OR & $95 \% \mathrm{Cl}$ & OR & $95 \% \mathrm{Cl}$ & OR & $95 \% \mathrm{Cl}$ \\
\hline \multicolumn{9}{|l|}{ Lunch source } \\
\hline School lunch & 1.00 & Reference & 1.00 & Reference & 1.00 & Reference & 1.00 & Reference \\
\hline Packed lunch & $0.19^{\star \star \star}$ & $0.11,0.35$ & $0.31^{\star \star \star}$ & $0.18,0.52$ & $0.60^{*}$ & $0.40,0.92$ & $0.56^{\star \star}$ & $0.37,0.86$ \\
\hline \multicolumn{9}{|l|}{ Gender } \\
\hline Boy & 1.00 & Reference & 1.00 & Reference & 1.00 & Reference & 1.00 & Reference \\
\hline Girl & 1.43 & $0.82,2.49$ & 1.40 & $0.84,2 \cdot 31$ & 1.44 & $0.95,2 \cdot 18$ & 1.46 & $0.96,2.22$ \\
\hline \multicolumn{9}{|l|}{ Grade } \\
\hline 4 & 1.00 & Reference & 1.00 & Reference & 1.00 & Reference & 1.00 & Reference \\
\hline 5 & 0.96 & $0.48,1.92$ & 0.97 & $0.52,1.79$ & $1.91^{*}$ & $1.14,3.18$ & 1.65 & $0.99,2.75$ \\
\hline 6 & 0.73 & $0.37,1.41$ & 1.01 & $0.55,1.83$ & 0.92 & $0.56,1.52$ & 0.98 & $0.59,1.61$ \\
\hline \multicolumn{9}{|l|}{ School } \\
\hline A & 1.00 & Reference & 1.00 & Reference & 1.00 & Reference & 1.00 & Reference \\
\hline$B$ & 0.56 & $0.23,1.40$ & $0.44^{\star}$ & $0.20,0.98$ & 1.05 & $0.56,1.99$ & 0.64 & $0.33,1.22$ \\
\hline $\mathrm{C}$ & 0.52 & $0.27,1.01$ & $0.44^{\star *}$ & $0.24,0.81$ & 0.91 & $0.56,1.50$ & 0.78 & $0.47,1.28$ \\
\hline
\end{tabular}

${ }^{\star} P<0.05,{ }^{* \star} P<0.01,{ }^{* \star \star} P<0.001$.

†Sample sizes differ due to missing data. 
Table 3 Associations between lunch source and quantities of fruit and vegetable contents and consumption (half-cup servings) among ( $\left.n_{\text {children }} 315\right)$ observed over five school days ( $\left.n_{\text {observations }} 1421\right)$, northern California, USA, January-April 2016†

\begin{tabular}{|c|c|c|c|c|c|c|c|c|}
\hline \multirow[b]{2}{*}{ Characteristic } & \multicolumn{2}{|c|}{$\begin{array}{c}\text { Fruit contents } \ddagger \\
\left(n_{\text {children }} 297,\right. \\
\left.n_{\text {observations }} 1156\right)\end{array}$} & \multicolumn{2}{|c|}{$\begin{array}{c}\text { Fruit consumption } \\
\left(n_{\text {children }} 264,\right. \\
\left.n_{\text {observations }} 804\right)\end{array}$} & \multicolumn{2}{|c|}{$\begin{array}{c}\text { Vegetable contents } \\
\left(n_{\text {children }} 260,\right. \\
\left.n_{\text {observations }} 707\right) \\
\end{array}$} & \multicolumn{2}{|c|}{$\begin{array}{c}\text { Vegetable consumption } \\
\left(n_{\text {children }} 241,\right. \\
\left.n_{\text {observations }} 572\right) \\
\end{array}$} \\
\hline & Mean & $95 \% \mathrm{Cl}$ & Mean & $95 \% \mathrm{Cl}$ & Mean & $95 \% \mathrm{Cl}$ & Mean & $95 \% \mathrm{Cl}$ \\
\hline \multicolumn{9}{|l|}{ Lunch source } \\
\hline School lunch & 1.11 & $1.04,1.17$ & $0.65^{a}$ & $0.59,0.71$ & 0.89 & $0.81,0.98$ & 0.58 & $0.51,0.65$ \\
\hline Packed lunch & 1.17 & $1.09,1.26$ & $0.86^{b}$ & $0.78,0.95$ & 0.77 & $0.68,0.87$ & 0.49 & $0.42,0.58$ \\
\hline \multicolumn{9}{|l|}{ Gender } \\
\hline Boy & 1.13 & $1.06,1.21$ & 0.77 & $0.69,0.84$ & 0.82 & $0.73,0.92$ & 0.55 & $0.47,0.63$ \\
\hline Girl & 1.15 & $1.09,1.22$ & 0.74 & $0.68,0.80$ & 0.84 & $0.77,0.92$ & 0.52 & $0.46,0.59$ \\
\hline \multicolumn{9}{|l|}{ Grade } \\
\hline 4 & $1.14^{\mathrm{a}}$ & $1.06,1.22$ & 0.77 & $0.69,0.85$ & 0.80 & $0.71,0.90$ & 0.56 & $0.48,0.65$ \\
\hline 5 & $1.08^{a}$ & $0.99,1.17$ & 0.72 & $0.64,0.81$ & 0.82 & $0.72,0.92$ & 0.48 & $0.40,0.56$ \\
\hline 6 & $1 \cdot 20^{\mathrm{b}}$ & $1 \cdot 12,1 \cdot 29$ & 0.77 & $0.69,0.85$ & 0.87 & $0.77,0.98$ & 0.57 & $0.49,0.67$ \\
\hline \multicolumn{9}{|l|}{ School } \\
\hline A & $1 \cdot 14^{a, b}$ & $1.05,1.24$ & $0.74^{a, b}$ & $0.65,0.83$ & 0.88 & $0.77,1.00$ & $0.64^{\mathrm{a}}$ & $0.54,0.75$ \\
\hline $\mathrm{B}$ & $1.28^{\mathrm{a}}$ & $1.17,1.39$ & $0.87^{\mathrm{a}}$ & $0.76,0.98$ & 0.88 & $0.75,1.01$ & $0.45^{\mathrm{b}}$ & $0.36,0.56$ \\
\hline $\mathrm{C}$ & $1.01^{\mathrm{b}}$ & $0.95,1.08$ & $0.66^{\mathrm{b}}$ & $0.60,0.73$ & 0.74 & $0.66,0.82$ & $0.53^{\mathrm{a}, \mathrm{b}}$ & $0.46,0.60$ \\
\hline
\end{tabular}

${ }^{\mathrm{a}, \mathrm{b}}$ For each characteristic separately, mean values within a column with unlike superscript letters were significantly different $(P<0.05)$.

†Fruit and vegetable outcomes represent instances where students included (contents) or ate (consumption) non-zero quantities (in half-cup servings), representing sub-samples of the full 1421 observations among 315 students.

‡Estimates are presented as least-squares means.

with when having a school lunch (OR $=0.60$ (95\% CI $0 \cdot 40$, 0.92), $P<0.05$; Table 2$)$. On days when vegetables were included $(54 \%$ of school and $45 \%$ of home-packed lunch observations), the quantities included were marginally less among home-packed lunches (mean $=0.77$ (95\% CI 0.68, 0.87) half-cup servings) than among school lunches (mean $=0.89 \quad(95 \%$ CI $0.81,0.98)$ half-cup servings, $P=0 \cdot 06$; Table 3 ).

\section{Vegetable consumption}

The probability of consuming vegetables was 0.45 when having a school lunch, compared with 0.31 when having a home-packed lunch. Students were $44 \%$ less likely to consume vegetables when having a home-packed lunch compared with when having a school lunch $(\mathrm{OR}=0.56$ (95\% CI 0.37, 0.86), $P<0 \cdot 01$; Table 2). On days when vegetables were consumed ( $47 \%$ of school and $41 \%$ of home-packed lunch observations), the quantities consumed were not significantly different between lunch sources, averaging approximately 0.5 half-cup servings of vegetables (Table 3).

\section{Discussion}

The present study investigated elementary-school students' lunchtime dietary behaviours in relation to lunch source. Building on prior research using observationbased studies and primarily addressing fruit and vegetable contents included in the lunch, the study compared contents as well as consumption between school and homepacked lunches. Understanding differences in fruit and vegetable dietary behaviours associated with lunch source may be informative to the design of school-based interventions targeting the lunchroom.

Fruit contents findings align with prior research in that the likelihood of including fruit was lower when having a home-packed lunch, compared with having a school lunch. However, it is important to note that fruit was frequently included in both lunch sources (90 and $72 \%$ of school and home-packed lunch observations, respectively). Updated nutrition standards for the NSLP likely contribute to the high probability of including fruit among school lunches because fruit selection has increased in response to these standards requiring students to select at least one-half cup of fruits or vegetables ${ }^{(20,33-35)}$. When fruits were included in the lunch, students' lunches contained an average of $1 \cdot 1$ half-cup servings (i.e. $0 \cdot 55$ cups) and quantities of fruit included did not differ by lunch source. In other words, when students' lunches did include fruits, quantities (on average) tended to meet NSLP nutrition standards for fruit ${ }^{(7)}$ and contributed $25-33 \%$ of Dietary Guidelines for Americans' recommendations for fruit for many youths within this age range ${ }^{(32)}$. Together, these findings suggest that interventions addressing lunchtime fruit contents are most needed to address whether or not fruit is included in the first place, particularly for home-packed lunches given the lower likelihood of these foods being included within this lunch source.

Fruit consumption was significantly less likely when students had home-packed lunches than when having school lunches, paralleling prior lunch comparisons addressing fruit contents ${ }^{(17,18)}$. However, when examining the average quantities of fruit consumed among those who did consume these foods, significantly greater quantities were consumed when students had home-packed lunches, consistent with prior research conducted prior to the 
implementation of updated NSLP nutrition standards ${ }^{(22)}$. Given that quantities of fruits included did not differ between school and home-packed lunches in the present study, greater consumption of fruits among home-packed lunches could reflect a tendency for home-packed lunches to include fruits that match student preferences, thus reducing food waste. This aligns with other plate waste research in finding a smaller proportion of fruits is wasted among home-packed lunches than school lunches ${ }^{(10,19,20,36-39)}$.

Students' lunches were significantly less likely to include vegetables when having home-packed lunches. Prior research found that $13-17 \%$ of home-packed and $29-61 \%$ of school lunches included vegetables ${ }^{(17,18)}$, which is relatively low compared with the present study for home-packed (45\%) and school lunches (54\%). This may reflect age-related differences, as the present study represents an older age group (grades 4-6) than earlier studies (pre-kindergarten to grade 2), and diet quality for vegetable consumption may increase as children progress from early childhood into adolescence ${ }^{(40)}$. The variability in estimates for vegetable contents among school lunches also suggests there may be other contextual influences affecting this dietary behaviour from day to day or across different schools. For example, vegetable contents could vary day-to-day in relation to the variety of vegetables offered in salad bars or in entrée items ${ }^{(41,42)}$. When students had vegetables in their lunch, there was a marginally significant trend where greater quantities were included when having a school lunch than when having a homepacked lunch. While vegetables were included in only half of all observations, the average quantities included when present were close to 1 serving ( 0.89 servings or 0.45 cups) in a school lunch and about $15 \%$ lower for homepacked lunches ( 0.77 servings or 0.39 cups). Given that a minority of students include any vegetables at lunchtime across both lunch sources, these findings suggest interventions should prioritize addressing whether or not any vegetables are included at lunchtime, as opposed to focusing on quantities included.

Students were significantly less likely to consume vegetables when having home-packed lunches, although the quantities of these foods consumed among vegetable consumers did not differ by lunch source. Finally, relative to fruit-related dietary behaviours, the probability of including and consuming vegetables was low, below 0.5 , indicating students are more likely to omit than to include these foods on a given day. Consumption of vegetables from school lunches has varied widely in previous studies, which estimate the percentage of these foods consumed to range from 27 to $70 \%^{(19,20,36-39)}$. Meanwhile, $70-77 \%$ of vegetable contents are consumed among home-packed lunches ${ }^{(10)}$. While having a home-packed lunch was associated with lower likelihood of consuming vegetables, there is a need for further promotion of these foods among all students regardless of lunch source.
In the present study, all models were adjusted for student gender, grade and school based on improved model fit, and significant associations between lunch source and dietary outcomes remained even after accounting for these covariates. Holding lunch source and other student characteristics (grade, gender) constant, there were significant differences in dietary behaviours between schools. These differences were not systematic and may relate to NSLP participation (e.g. as a proxy for socio-economic status) or other school characteristics beyond the scope of the present study but explored in other research, such as time available to eat ${ }^{(36,43,44)}$ or student-teacher relationships at lunchtime ${ }^{(45)}$. Meanwhile, dietary behaviours generally did not differ by grade or by gender. Prior research documents a decline in fruit consumption during childhood and adolescence, while vegetable consumption exhibits a more stable or inconsistent pattern $^{(3,40,46)}$. A similar decline in fruit consumption was not observed in the present study based on grade-level differences, although the age range covered in the study was relatively narrow. While studies have reported greater consumption of fruits and vegetables among girls than boys ${ }^{(3,46)}$, no gender differences were observed in the final models in the present study.

Strengths of the present study include its use of multiple days of observations to capture reliable estimates of dietary behaviours over the school week, as well as its use of an objective digital imaging method to minimize respondent burden and measurement error when assessing lunchtime diets. In addition, the study examined a student sample size within the range of prior lunch comparison studies $^{(10,12,22)}$, while incorporating repeated observations to yield over 1400 observations. However, there were important limitations to the present study that should guide future research. First, we cannot rule out the potential for measurement error due to reactivity if students' dietary behaviours change in response to the presence of researchers. Preliminary observations were conducted in each lunchroom ahead of the official observation periods to acclimatize students to the presence of researchers. Observation-based methods such as digital imaging are advantageous over self-report methods to mitigate several sources of measurement error (e.g. omissions or intrusions due to poor memory retention, misestimation of portion sizes) ${ }^{(23)}$. Nevertheless, further research on observation-based methods, particularly digital imaging, is needed to better understand whether, and to what degree, being observed may alter behaviour.

Second, while the present study's sample was diverse in terms of race/ethnicity and socio-economic characteristics, it was restricted to three schools. While all schools participating in the NSLP follow the same federal nutrition standards, there may be differences in how each implements the programme. For example, all schools within the present study offered a variety of fruit and vegetable options daily as part of salad bars, which may increase 
contents and consumption of these foods in school lunches, relative to schools without salad bars ${ }^{(47,48)}$. Future research should consider how these food environment characteristics may shape dietary behaviours among school lunches, via school-to-school and day-to-day variation in fruit and vegetable availability within the school lunch menu. Similarly, variations in home fruit and vegetable availability should be examined in relation to home-packed lunches.

\section{Conclusion}

Youths' consumption of fruits and vegetables falls well below national recommendations and schools are opportune contexts for promoting these behaviours as part of obesity and chronic disease prevention strategies. While federal nutrition standards for the NSLP can target dietary behaviours among students having school lunches, many bring packed lunches from home, which are not subject to these standards. The present study found that students having home-packed lunches are less likely to include and to consume fruits and vegetables, although quantities included and consumed did not follow the same systematic pattern. Participation in the NSLP may encourage youths to establish healthy dietary behaviours during the school day and these findings aid in identifying areas for improving fruit and vegetable dietary behaviours, particularly among students having home-packed lunches. For instance, students having home-packed lunches were less likely to consume any vegetables, but when vegetables were consumed, the amount eaten did not differ between lunch sources. These findings suggest interventions tailored towards parents and youths preparing home-packed lunches should focus on encouraging more frequent inclusion of fruits and vegetables across the school week, while less emphasis may need to be placed on how much to pack. Encouraging more frequent inclusion, and ultimately consumption, of vegetables is particularly needed given that vegetables were included in only half of lunch observations. These combined findings are informative to designing nutrition interventions targeting dietary behaviours at school to establish and maintain healthy dietary behaviours from an early age.

\section{Acknowledgements}

Acknowledgements: The authors thank the participants for their involvement in this project, as well as the principals, teachers, school nutrition services and other staff that provided support during this project. They thank the team of research assistants at the University of California, Davis, for their contributions to data collection and processing, and thank Dr Nancy Keim for her critical input to drafts of this manuscript. Financial support: This research was supported by a University of California, Davis Academic Federation Innovative Development Grant (L.L.O., A.N.); the University of California, Davis Henry A. Jastro Scholarship Fund (J.C.T., C.S.); and a University of California, Davis Graduate Studies Fellowship (J.C.T.). The funders had no role in the design, analysis or writing of this article. Conflict of interest: J.C.T. reports personal fees from Freeli Foods, outside the submitted work. Authorship: J.C.T., C.S., L.L.O., A.N. and S.Z.-C. contributed to the design of this study. J.C.T. and C.S. managed the study and carried out all data collection and processing. J.C.T. conducted the data analyses and initial drafting of the manuscript. C.S., L.L.O., A.N. and S.Z.-C. contributed to final drafting and editing of the manuscript. Ethics of buman subject participation: This study was conducted according to the guidelines laid down in the Declaration of Helsinki and all procedures involving human subjects were approved by the University of California, Davis, Institutional Review Board. Written informed parental consent and student assent was obtained for all participants.

\section{References}

1. Ambrosini GL (2014) Childhood dietary patterns and later obesity: a review of the evidence. Proc Nutr Soc 73, 137-146.

2. Wang X, Ouyang Y, Liu J et al. (2014) Fruit and vegetable consumption and mortality from all causes, cardiovascular disease, and cancer: systematic review and dose-response meta-analysis of prospective cohort studies. BMJ $\mathbf{3 4 9}$, g4490.

3. Hiza HAB, Casavale KO, Guenther PM et al. (2013) Diet quality of Americans differs by age, sex, race/ethnicity, income, and education level. I Acad Nutr Diet 113, 297-306.

4. Kim SA, Moore LV, Galuska D et al. (2014) Vital signs: fruit and vegetable intake among children - United States, 20032010. Morb Mortal Wkly Rep 63, 671-677.

5. Weber K \& Chen T (2017) The contribution of the USDA school breakfast and lunch program meals to student daily dietary intake. Prev Med Rep 5, 82-85.

6. Gordon A, Fox MK, Clark M et al. (2007) School Nutrition Dietary Assessment Study-III: Vol. II: Student Participation and Dietary Intakes. Alexandria, VA: US Department of Agriculture, Food and Nutrition Service, Office of Research, Nutrition and Analysis; available at http://www.fns.usda. gov/sites/default/files/SNDAIII-Vol2.pdf

7. Food and Nutrition Service, US Department of Agriculture (2012) Nutrition standards in the National School Lunch and School Breakfast Programs. Final rule. Fed Regist 77, 4088-4167.

8. Cullen KW \& Dave JM (2017) The new federal school nutrition standards and meal patterns: early evidence examining the influence on student dietary behavior and the school food environment. I Acad Nutr Diet 117, 185-191.

9. Food and Nutrition Service, US Department of Agriculture (2012) School Nutrition Dietary Assessment Study IV. Alexandria, VA: Food and Nutrition Service, USDA.

10. Caruso ML \& Cullen KW (2015) Quality and cost of student lunches brought from home. JAMA Pediatr 169, 86-90.

11. Romo-Palafox MJ, Ranjit N, Sweitzer SJ et al. (2015) Dietary quality of preschoolers' sack lunches as measured by the Healthy Eating Index. J Acad Nutr Diet 115, 1779-1788. 
12. Hubbard KL, Must A, Eliasziw M et al. (2014) What's in children's backpacks: foods brought from home. J Acad Nutr Diet 114, 1424-1431.

13. Romo-Palafox MJ, Ranjit N, Sweitzer SJ et al. (2017) Adequacy of parent-packed lunches and preschooler's consumption compared to dietary reference intake recommendations. J Am Coll Nutr 36, 1-8.

14. Minaya S \& Rainville AJ (2016) How nutritious are children's packed school lunches? A comparison of lunches brought from home and school lunches. J Child Nutr Manag $\mathbf{4 0}$, issue 2, 1-7.

15. Goldberg JP, Folta SC, Eliasziw M et al. (2015) Great Taste, Less Waste: a cluster-randomized trial using a communications campaign to improve the quality of foods brought from home to school by elementary school children. Prev Med 74, 103-110.

16. Roberts-Gray C, Briley ME, Ranjit N et al. (2016) Efficacy of the Lunch is in the Bag intervention to increase parents' packing of healthy bag lunches for young children: a cluster-randomized trial in early care and education centers. Int J Behav Nutr Phys Act. 13, 3.

17. Johnston CA, Moreno JP, El-Mubasher A et al. (2012) School lunches and lunches brought from home: a comparative analysis. Child Obes 8, 364-368.

18. Farris AR, Misyak S, Duffey KJ et al. (2014) Nutritional comparison of packed and school lunches in prekindergarten and kindergarten children following the implementation of the 2012-2013 National School Lunch Program standards. J Nutr Educ Behav 46, 621-626.

19. Cullen KW, Chen T-A, Dave JM et al. (2015) Differential improvements in student fruit and vegetable selection and consumption in response to the new National School Lunch Program regulations: a pilot study. J Acad Nutr Diet $\mathbf{1 1 5}$ 743-750.

20. Schwartz MB, Henderson KE, Read M et al. (2015) New school meal regulations increase fruit consumption and do not increase total plate waste. Child Obes 11, 242-247.

21. Farris AR, Misyak S, Duffey KJ et al. (2016) Elementary parent perceptions of packing lunches and the National School Lunch Program. J Child Nutr Manag 40, issue 1, 1-10.

22. Hur I, Burgess-Champoux T \& Reicks M (2011) Higher quality intake from school lunch meals compared with bagged lunches. ICAN Infant Child Adolesc Nutr 3, 70-75.

23. Thompson FE \& Subar AF (2013) Dietary assessment methodology. In Nutrition in the Prevention and Treatment of Disease, 3rd ed., pp. 5-46 [AM Coulston, CJ Boushey, MG Ferruzzi, editors]. London: Elsevier.

24. van Staveren WA, Ocké MC \& de Vries JHM (2012) Estimation of dietary intake. In Present Knowledge in Nutrition, 10th ed., pp. 1012-1026 [JW Erdman, IA Macdonald and SH Zeisel, editors]. Oxford: Wiley-Blackwell.

25. Ollberding NJ, Couch SC, Woo JG et al. (2014) Within- and between-individual variation in nutrient intake in children and adolescents. J Acad Nutr Diet 114, 1749-1758.

26. Martin CK, Newton RL, Anton SD et al. (2007) Measurement of children's food intake with digital photography and the effects of second servings upon food intake. Eat Behav 8, 148-156.

27. Sutter C, Taylor JC, Nishina A et al. (2016) Parenting and the contents of home-packed lunches for elementary-age youth. Natl Counc Fam Relations Rep Summer issue, F10-F11.

28. Taylor JC, Yon BA \& Johnson RK (2014) Reliability and validity of digital imaging as a measure of schoolchildren's fruit and vegetable consumption. J Acad Nutr Diet 114, 1359-1366.

29. Taylor JC, Sutter C, Ontai L et al. (2018) Reliability of a digital imaging-based method for estimating food selection and consumption from packed lunches. Appetite 120, 196-204.

30. Williamson DA, Allen HR, Martin PD et al. (2003) Comparison of digital photography to weighed and visual estimation of portion sizes. J Am Diet Assoc 103, $1139-1145$.

31. Schakel SF, Jasthi B, Van Heel N et al. (2009) Adjusting a nutrient database to improve calculation of percent calories from macronutrients. J Food Compost Anal 22, Suppl., S32-S36.

32. US Department of Health and Human Services \& US Department of Agriculture (2015) Dietary Guidelines for Americans 2015-2020, 8th ed. Washington, DC: US DHHS and USDA.

33. Amin SA, Yon BA, Taylor JC et al. (2015) Impact of the National School Lunch Program on fruit and vegetable selection in Northeastern elementary schoolchildren, 20122013. Public Health Rep 130, 453-457.

34. Cullen KW, Chen TA \& Dave JM (2015) Changes in foods selected and consumed after implementation of the new National School Lunch Program meal patterns in southeast Texas. Prev Med Rep 2, 440-443.

35. Cohen JFW, Richardson S, Parker E et al. (2014) Impact of the new US Department of Agriculture school meal standards on food selection, consumption, and waste. Am J Prev Med 46, 385-391.

36. Cohen JFW, Jahn JL, Richardson S et al. (2016) Amount of time to eat is associated with children's selection and consumption of school meal entree, fruits, vegetables, and milk. J Acad Nutr Diet 116, 123-128.

37. Cohen JFW, Richardson S, Austin SB et al. (2013) School lunch waste among middle school students: nutrients consumed and costs. Am J Prev Med 44, 114-121.

38. Gray C, Lytle LA, Perry C et al. (2007) Fruits and vegetables taken can serve as a proxy measure for amounts eaten in a school lunch. J Am Diet Assoc 107, 1019-1023.

39. Smith SL \& Cunningham-Sabo L (2014) Food choice, plate waste and nutrient intake of elementary- and middle-school students participating in the US National School Lunch Program. Public Health Nutr 17, 1255-1263.

40. Banfield EC, Liu Y, Davis JS et al. (2016) Poor adherence to US dietary guidelines for children and adolescents in the National Health and Nutrition Examination Survey population. J Acad Nutr Diet 116, 21-27.

41. Adams MA, Pelletier RL, Zive MM et al. (2005) Salad bars and fruit and vegetable consumption in elementary schools: a plate waste study. J Am Diet Assoc 105, 1789-1792.

42. Branum AM \& Rossen LM (2013) The contribution of mixed dishes to vegetable intake among US children and adolescents. Public Health Nutr 17, 2053-2060.

43. Townsend N (2015) Shorter lunch breaks lead secondaryschool students to make less healthy dietary choices: multilevel analysis of cross-sectional national survey data. Public Health Nutr 18, 1626-1634.

44. Zandian M, Ioakimidis I, Bergström J et al. (2012) Children eat their school lunch too quickly: an exploratory study of the effect on food intake. BMC Public Health 12, 351.

45. Osowski CP, Göranzon H \& Fjellström C (2013) Teachers' interaction with children in the school meal situation: the example of pedagogic meals in Sweden. J Nutr Educ Behav 45, 420-427.

46. Albani V, Butler LT, Traill WB et al. (2017) Fruit and vegetable intake: change with age across childhood and adolescence. Br J Nutr 117, 759-765.

47. Adams MA, Bruening M \& Ohri-Vachaspati P (2015) Use of salad bars in schools to increase fruit and vegetable consumption: where's the evidence? J Acad Nutr Diet 115, 1233-1236.

48. Johnson CC, Myers L, Mundor AR et al. (2017) Lunch salad bars in New Orleans' middle and high schools: student intake of fruit and vegetables. Int I Environ Res Public Health 14, E415. 